\title{
Uma epistemologia genética dos ecossistemas de desinformação? Problema interdisciplinar / resposta transdisciplinar
}

\author{
A genetic epistemology of disinformation ecosystems? Interdisciplinary problem / transdisciplinary response \\ Claudio Paixão Anastácio de Paula \\ Universidade Federal de Minas Gerais. Escola de Ciência \\ da Informação, Brasil \\ claudiopap@hotmail.com \\ https://orcid.org/0000-0001-9587-2191
}

\begin{abstract}
Resumo:
Este ensaio sugere bases bio-psico-histórico-sociais de uma possível abordagem do campo informacional com vistas ao combate da desinformação a partir da compreensão da ecologia mental que a sustenta. Propõe-se uma ponte conceitual entre as concepções de schème (palavra que poderia ser traduzida em português como esquema mental) em Jean Piaget e Gilbert Durand, avaliando a adequação de sua incorporação a uma epistemologia crítica do campo e, consequentemente, à criação de uma abordagem integradora para as teorias que se dedicam ao entendimento do conceito de informação. Caracteriza-se a ecologia mental da desinformação entendendo a sustentação da disseminação e da crença em informações falsas a partir da sua abordagem através da transposição dos modelos evolutivos de transferência de informações culturais propostos pela memética para o campo informacional. Finalmente, propõe-se um paralelo entre: 1) a utilização do termo schèma (em tradução aproximada para o português; esquema representado, diagrama) e da teoria da schematization pela Escola Esquematista da Ciência da Informação e 2) uma possível utilização do conceito schème e uma teoria da schemetization para sustentar a necessidade de construção de base para a redefinição do campo informacional. Argumenta-se que essa redefinição é suscitada pela condição hipermoderna e que, a partir da abertura disciplinar para diálogos teóricos entre as visões sociais, cognitivas, tecnológicas, políticas e econômicas envolvidas dos problemas infocomunicacionais, se possa definir um território informacional propositivo e voltado para a solução de questões prementes como a urgência da alfabetização midiática e de conscientização para a importância da comunicação online numa perspectiva crítica.
\end{abstract}

Palavras-Chave: Desinformação, Schème e schemetization, Transdisciplinaridade, Escola Esquematista da Ciência da Informação, Memética.

\begin{abstract}
:
This essay suggests the possible bio-psycho-historical-social bases for addressing the informational field with a view to combating disinformation from the understanding of the mental ecology that sustains it. A conceptual bridge between the conceptions of scheme (mental scheme, in English) in Piaget and Gilbert Durand is proposed, evaluating the adequacy of its incorporation to a critical epistemology of the field and, to the creation of a integrative approach to theories dedicated to understanding the information concept. The mental ecology of disinformation is characterized, seeking to understand the support of dissemination and belief in false information from its approach through a transposition of the evolutionary models of transferring cultural information proposed by memetics to the information field. Finally, a parallel is proposed between: 1) the use of the term schema (in approximate translation into English; diagram represented, diagram) and the theory of schematization by the Schematist School of Information Science and 2) a possible use of the concept of scheme and a theory of schemetization to support the need for building a base for redefining the information field. It is argued that this redefinition is motiveted by the hypermodern condition and it is considered that, from the disciplinary opening for theoretical dialogues between the social, cognitive, technological, political and economic views involved in the infocommunication problems, it is possible to define a propositional informational territory aimed for the solution of issues such as the urgency of a media literacy conscious of the importance of consider online communication in a critical perspective.
\end{abstract}

KeYwords: Disinformation, Schème and schemetization, Transdisciplinarity, Schematist School of Information Science, Memetics. 


\section{A evolução de um cenário que aponta para a necessidade de uma solução EPISTEMOLÓGICA INTERDISCIPLINAR}

Quando McLuhan, nos anos de 1960, baseou-se em Walter Benjamin para afirmar que a invenção da imprensa havia destribalizado o mundo retirando-o de um coletivismo tribal e colocando-o na direção de um individualismo moderno mediado pelo livro (McLuhan, 1994) que caminharia daí para a emergencia de uma aldeia global mediada pela comunicação de massa, ele não tinha ainda a dimensão das transformações que a sociedade iria sofrer nos anos seguintes ao ter sua estrutura permeada pela mediação dos meios eletrônicos de informação móvel. A aldeia global foi rapidamente superada por um processo de coletivismo eletrônico que viria a ser descrito por Maffesoli (2007) como um tribalismo pós-moderno (ou hipermoderno). ${ }^{1}$ Nesse cenário, sob a interferência da troca quase instantânea de informações, a alteridade muitas vezes sucumbe à ação daquilo que Boechat (2018) irá denominar epidemias psíquicas em política e em outras áreas do domínio social.

Ainda evocando metaforicamente imagens do passado, há que se ressaltar que muitas dessas epidemias são fruto de ações cuidadosamente orquestradas para atender interesses particulares da mesma forma como, a partir da distribuição de cobertores infectados, foi manipulada a epidemia de varíola que levou à destruição a tribo dos insurrectos Goitacazes (Bueno, 1999). Exemplos dessa condição tribalística para espalhar contaminações, agora pela via virtual, são diversos. Vão do escândalo do uso de dados do Facebook pela empresa Cambridge Analytica e a consequente manipulação desta e de outras redes sociais segundo os interesses de um grupo político para propaganda eleitoral nos Estados Unidos (bem como seu correlato na manipulação das redes sociais durante as eleições presidenciais no Brasil) até a manipulação criminosa das crenças a partir de mentiras cuidadosamente disseminadas via internet. Essa manipulação e distribuição delivery de mentiras nos aparelhos celulares permitiu que o fenômeno hoje descrito pelo eufemismo pósverdade, atingisse um paroxismo nunca antes imaginado e afetasse o comportamento de populações inteiras através do concurso da intensa disseminação de notícias falsas (as chamadas fake news).

Essas intervenções, orquestradas para alterar a percepção das pessoas, conseguiram promover o idiota da aldeia (Eco, 2017) - que antes necessitava da presença física do público que se reunia em torno dele nos bares de sua comunidade para disseminar suas ideias equivocadas - ao lugar de portador da verdade e pilar da construção de uma realidade alternativa onde milhares de pessoas passaram a habitar. Ao reeditarem ideias como o terraplanismo e o marxismo cultural, ${ }^{2}$ eles levaram o idiota de Eco, ora ao lugar de porta-voz que possui elequência suficiente para propagar ideias concebidas intencionalmente para criar desinformação (como ações antivacina, por exemplo), disseminar crenças anticientíficas (como o criacionaismo) e espalhar narrativas conspiratórias com o objetivo de combater "ideias revolucionárias perigosas" (como os direitos humanos e promoção do respeito à diversidade); ora ao lugar de testa de ferro que concederia cargos e funções a outros do seu gênero e assim facultaria o acesso ao espaço público para outros disseminadores mais eficientes de mentiras.

Nesse contexto, temas como ecossistemas de desinformação, algoritmos de redes sociais, capitalismo de vigilância e bots de internet passam a extrapolar o domínio das ciências da computação e da informação, passando a se tornar tema de investigação e questionamento de filósofos, antropólogos, educadores, sociólogos, psicólogos, historiadores e toda uma sorte de outros domínios de conhecimento atualmente considerados malditos em algumas esferas da ação política (como pode ser reconhecido, no caso particular do Brasil, nos frequentes ataques verbais e administrativos desferidos pelo atual ocupante do palácio presidencial brasileiro e seus sucessivos e problemáticos ministros da educação às instituições universitárias e científicas, em geral, e aos cursos da área das humanidades em particular).

No entanto, o entendimento aprofundado da ação desses fenômenos na esfera subjetiva e a sua expressão nas ações coletivas e nas suas expressões concretas não pode abrir mão do concurso de referências advindas ainda de outros campos do pensamento. Esses novos campos, além da antropologia do imaginário (campo 
transdisciplinar por natureza), vão invocar desde a participação das teorias econômicas (para o entendimento das condições necessárias e suficientes para a sua proliferação no mercado), passando pelas neurociências (para que possa ser embasada uma apreciação mais aprofundada da relação entre as informações e a produção de sentido delas extraída) até campos ainda em desenvolvimento como a memética (que, a partir da aplicação de conceitos da teoria da genética populacional ao estudo da cultura humana, pode oferecer um novo ponto de inflexão para o entendimento da propagação das crenças no meio virtual) baseada nas propostas de Dawkins (2007).

O que fica evidente, ao se contemplar a multiplicidade de situações que tem a informação como tema central a partir do caso específico da crença em informações falsas, é que o fenômeno "informação" escapa ao domínio de uma só disciplina (ou mesmo das disciplinas que a tem como uma preocupação mais evidente). Por se tratar de um objeto interdisciplinar, uma abordagem ideal ao fenômeno informacional deveria incorporar um esforço para superar a divisão artificial (e que muitas vezes parece natural) entre as áreas do conhecimento. Em outras palavras, faz-se necessário um esforço transdisciplinar para abordar um objeto interdisciplinar.

Nesse sentido, é urgente dar seguimento ao desafio de promover a valorização das contribuições de pesquisadores (psicólogos, filósofos, administradores, bibliotecários, historiadores, bacharéis em sistemas de informação e jornalistas) que, em suas diferentes formações em nível de Pós-graduação (filosofia, arquivologia, ciência da informação, psicologia social, comportamento organizacional, marketing, administração) e em sua militância em áreas que muitas vezes não dialogam entre si com a frequência desejada (com destaque para a gestão e a organização do conhecimento, a antropologia, a antropologia do imaginário, a pedagogia, as psicologias do inconsciente e as teorias cognitivas) e de seus diferentes territórios. Porém, é necessário fazê-lo com a intenção concreta de promover entre eles um intercâmbio permanente, propício para a formação constante de novos territórios que estejam a altura da oportunidade de se trabalhar um objeto interdisciplinar por excelência (a informação) e tomá-la como uma alternativa para se chegar à transdisciplinaridade e um estágio no qual a investigação do fenômeno informacional não ficaria mais limitada pelas fronteiras entre as disciplinas e se beneficiaria constantemente das contribuições de outras fontes e estratos de conhecimento.

Destaque-se, aqui que não se trata de simpesmente afirmar a ciência da informação (CI) como uma "ciência interdisciplinar", mas sim de torna-la de fato interdisciplinar não apenas aceitando (como é usual) que pesquisadores de diversas áreas venham beber de seus princípios, mas de incorporar as contribuições (ainda que sopesando aproximação e distanciamento crítico) das diversas áreas no sentido de uma ampliação do campo. A partir daí seria possível: 1) retomar as procupações iniciadas nos primeiros anos do século XXI que ressaltavam a necessidade premente do estabelecimento de estratégias para o gerenciamento de competências e do comportamento informacional em uma sociedade transformada pelo "culto à urgência" - descrito por Aubert (2003) -; 2) de efetuar a transposição dos conhecimentos acumulados pela CI ao longo das últimas duas décadas de sua existência para uma investigação que aponte na direção de resultados práticos como a criação de estratégias para a alfabetização midiática e a conscientização para a importância da comunicação online; e 3) de propor contribuiçóes que possam ser utilizadas futuramente para o desenvolvimento de uma perspectiva de trabalho ampla que contribua para entrelace necessário entre as áreas da comunicação, computação, direito e informação (na discussão de situações pontuais e urgentes como, no caso brasileiro, a polêmica em torno da Lei Geral de Proteção dos Dados, por exemplo), mas que considere também os aspectos subjetivos, subjacentes e inconscientes envolvidos nos fenômenos inforcomunicacionais não pode ser desperdiçada. 


\section{Do CONCEITO DE ECOlOgia DA INFORMAÇÃo À UMA PROPOSTA DE INVESTIGAÇÃo DA ECOLOGIA DA DESINFORMAÇÃO}

A ecologia da informação (Davenport, 1998) e os seus distúrbios dentro do ambiente permeado pela cultura da urgência, especialmente quando matizada pela interferência de crenças e narrativas enraizadas no imaginário, tem sido uma preocupação recorrente em alguns estudos na Ciência da Informação desenvolvida no Brasil. Essa preocupação tem figurado nessas pesquisas de forma descentralizada e agora, diante do momento de efervescência política que marcou a virada da segunda para a terceira década do século XXI, surge a oportunidade de aprofundamento desses estudos embrionários sob a forma de contribuição à sociedade e à academia.

A expressão "cultura da urgência" foi usada por Aubert (2003) para descrever a condição de aumento das demandas por reações rápidas na sociedade do início do século XXI. Essa condição implica numa mudança na percepção e na avaliação do desempenho: se, antes, um indivíduo ou um sistema era considerado eficiente porque mantinha um ritmo coerente de desempenho por um período relativamente longo de tempo, recentemente esse mesmo indivíduo ou sistema será percebido como excelente pela sua performance em um determinado instante. Uma concepção ilusória de excelência onde a melhor resposta é sempre aquela obtida no menor tempo. Esse cenário e suas implicações na comunicação atual foram amplamente discutidos por Paula (2011, 2012b) como um desdobramento natural de estudos anteriores (Paula, 1999, 2005), com a proposição de uma alternativa de investigação que considerasse o uso afetivo e simbólico da informação pelo sujeito (muitas vezes em bases inconscientes) como um recurso de acesso às expressóes da subjetividade desse mesmo sujeito nas interações com a informação.

À época foi proposta uma abordagem que se apresentou como uma alternativa de investigação em um cenário onde as possibilidades ampliadas de comunicação e a velocidade de produção e disseminação da informação alteravam radicalmente as práticas e as relações dos sujeitos com ela. A demanda crescente por velocidade não somente de acesso, mas também de resposta às demandas da comunidade conectada, discutidas anteriormente, aprofundou esse cenário através de uma reconfiguração peculiar das escolhas e decisóes que passaram a se basear mais em reações afetivas do que nos preceitos racionais propostos pelos teóricos da informação (Paula, 2013).

Dentro dessa perspectiva, começaram a se delinear estudos que se propõe, entre outros pontos, a analisar a hermenêutica das dimensões simbólicas e afetivas inerentes aos processos de buscar, selecionar, interpretar e utilizar informações. Uma série de investigações - Antunes (2015); Araújo (2013, 2017); Paula (2011, 2012a); Pedrosa (2017), Queiroz (2014, 2019); Sá (2015); e Rocha (2018) - reuniram um repertório de práticas de investigação e consolidaram contribuições para a área num terreno em constante transformação onde começaram a ser consideradas as múltiplas dimensões em que os símbolos e os afetos se entrelaçam para compor o tecido que subjaz a relação das pessoas com a informação. Dentro das perspectivas abarcadas pela por esses estudos, convencionou-se chamar esse tecido "o imaginário".

A partir da proposição de uma abordagem ampla da informação (que o autor denominou Abordagem Clínica da Informação - ACI), Paula (2011, 2012b) sugere a possibilidade de se abordar os indivíduos em suas múltiplas dimensões de interação com a informação (linguística, simbólica, cognitiva, afetivoemocional) dentro de uma perspectiva de busca de informação como um processo histórico, social, cultural, experiencial e contingencial. Ainda segundo Paula (2012b), essa abordagem deveria se basear nas noções de que: 1) a interação entre indivíduos e a informação é indissociável da sua inserção nos grupos sociais a que pertencem; 2) o comportamento de busca por informações (e seus desdobramentos) é determinado pela inserção do sujeito informacional em grupos sociais e é um processo experimental e contingencial, consciente ou inconscientemente marcado pelos campos psíquico, cultural, histórico e social; e, finalmente, 3) de que o campo psíquico é composto indissociavelmente pelas dimensões cognitiva, perceptiva e afetiva, sendo que esse campo tanto influencia quanto é influenciado pelos campos cultural, histórico e social. 
Essa amplitude de relações evidenciou que, em virtude da natureza complexa do tecido que elas compõem, os instrumentos padronizados não são suficientes para apreender as múltiplas dimensões da relação entre indivíduos e a informação, fato que também impossibilita que, em termos de matérias e métodos, as investigações nesse campo sejam feitas através da utilização de um único instrumento (Paula, 2012b). Nessa direção tem sido propostas novas abordagens do fenômeno infocomunicacional que busquem, na investigação atenta desse objeto, através do concurso de teorias e ferramentas originárias de múltiplos domínios teóricos, criar formas investigar a informação, enquanto um objeto de estudo, a partir do reconhecimento amplo de seus estados, padrões, movimentos e alterações. Desse modo, acreditam-se os autores desse grupo, ser possível descrever fenômenos, tecer diagnósticos, prognósticos ou prescrever intervenções no campo da informação com muito mais precisão.

Uma vez que, na maioria das vezes, é impossível determinar a situação e o contexto originais em que foram criadas muitas das informações promotoras de crenças e mensagens falsas para chegar a uma compreensão da sua dinâmica, da gênese de sua condição atual e do seu processo histórico único, torna-se urgente desenvolver uma busca intensa pelos "comos" e os "porquês" determinantes da ampla penetração dessas informações (que, apesar de falsas, contemplam uma poderosa carga de significados subjetivos) no imaginário de seu público.

Para que isso seja possível, é necessário traçar uma reflexão geral em torno da natureza e das etapas através das quais circulam as informações em geral. Essa tarefa seria pré-requisito para possibilitar: a compreensão da forma como esses processos se dão na desinformação; a busca de um ângulo ampliado de utilização da teoria do conhecimento voltado para compreender a modalidade do conhecer que sustenta a desinformação; um estudo dos postulados, conclusões e, métodos nos quais baseia o ato de conhecer para se possa entender como a desinformação é apreendida e disseminada; e, finalmente, identificar o conjunto dos fatos ou elementos que concorrem para a formação da informação. Dito de outro modo, sugere-se que, através de uma epistemologia genética da informação, se possa chegar a uma epistemologia genética da desinformação.

A expressão epistemologia genética é resgatada aqui por evocar a teoria do conhecimento proposta por Piaget e que busca entender cientificamente a perpetuação do conhecimento (em suas possibilidades e limitações), seu surgimento e o seu desenvolvimento (RamozzI-Chiarottino, 1988) através da aplicação do método clínico (Obana, 2015). ${ }^{3}$

Poder-se-ia perguntar nesse ponto se, dada a confusão frequente entre os termos informação e conhecimento (como bem descrevem Xavier e Costa, 2010), propor uma epistemologia genética da informação não seria uma redundância? Polêmicas a parte, a resposta é não. O termo epistemologia genética da informação é usado aqui para designar a busca da origem e das bases da capacidade de conhecer que sustenta e organiza a informação.

Ao retomar, nesses termos, o conceito de ecologia da informação (Davenport, 1998) a partir do esforço proposto acima e, de certa forma, subvertendo-o, torna-se possível pensar na existência de um ou mais ecossistemas de desinformação que precisam ser compreendidos para serem combatidos.

Se existe o objetivo de se construir intervenções e estratégias no campo da alfabetização midiática e para a conscientização quanto à importância da comunicação online, é fundamental que seja construído um entendimento o mais amplo possível desses ecossistemas de desinformação. Talvez até mesmo investigar a possibilidade da existência de um subsistema mental que o sustente e do processo "ecológico" por trás dele. É na direção dessa tarefa que o presente ensaio aponta.

\section{3. À guisa de Metodologia: OU, PORQue, EM tempos DE “Opiniões", ATÉ os ENSAios DEVEM SEGUIR UM MÉTODO}

As razões, ainda que óbvias, para que se apresentem as reflexões sob um cunho ensaístico, os cuidados suscitados por essa opção e, simultaneamente, as preocupações que devam ser consideradas a partir daí, são apresentadas a seguir. 
Num momento em que a distinção entre os conteúdos profissonais e amadores é frequentemente anulada (Keen, 2008) e que a relevância dada às opinióes pouco ou nada fundamentadas em dados (ou, pelo menos, em raciocínios filosóficamente consistentes) recrudece, torna-se necessário que as reflexões, mesmo em se tratando de ensaios, busquem se afastar das meras opiniões ou da celebração de conteúdos amadores submetendo-se a critérios (e deixando-os explícitos) que possam reger o corpo de conhecimentos escolhidos para serem percorridos na busca de resposta às questões propostas. A alternativa mais viável para esse delineamento é associação entre a aparente liberdade atribuída ao ensaio um tipo específico de estudo de revisão: a revisão de tipo integrativo. Essa forma de estudo tem sua origem, modus operandi e potenciais definidos da seguinte forma:

surgiu como alternativa para revisar rigorosamente e combinar estudos com diversas metodologias, por exemplo, delineamento experimental e não experimental, e integrar os resultados. Tem o potencial de promover os estudos de revisão em diversas áreas do conhecimento, mantendo o rigor metodológico das revisões sistemáticas. O método de revisão integrativa permite a combinação de dados da literatura empírica e teórica que podem ser direcionados à definição de conceitos, identificação de lacunas nas áreas de estudos, revisão de teorias e análise metodológica dos estudos sobre um determinado tópico. A combinação de pesquisas com diferentes métodos combinados na revisão integrativa amplia as possibilidades de análise da literatura (Biblioteca Dante Moreira Leite, s.d.).

Sob esse cuidado, receberão destaque, as ideias derivadas de autores como Carl Jung, Gilbert Durand, Jean Piaget e alguns de seus respectivos continuadores (para que seja aprofundada a discussão sobre as relações entre reflexos, schèmes e arquétipos e a gênese da relação do humano com a informação); de autores como Richard Dawkins, Susan Blackmore e Daniel Dennett, entre outros (ao se abordarem os resultados de seus insights sobre a memética em geral e de temas específicos como variação memética e associação memética), e, finalmente, reflexões inspiradas pelos estudos "de e sobre" Paul Otlet, Nicolas Roubakine e Gabriel Peignot, autores propostos por Gustavo Saldanha como antecessores da Escola Esquematista da Ciência da Informação de Robert Estivals (de onde foi emprestada a noção de schematization).

Finalmente, é necessário que se chegue à escolha do ensaio como a forma principal de apresentação dos dados, e é fundamental deixar claro que a análise dos dados nessa modalidades de investigação está indelevelmente associada tanto aos processos de experimentação intelectual quanto à própria leitura e a preparação do material a partir do qual o estudo será conduzido.

Recorrendo a Bense (2014, não paginado), uma vez que o ensaio tem a sua origem na essência crítica, a experimentação na prática ensaística é uma derivação direta dessa essência, do seu método - por assim dizer. Nas palavras do autor:

o ensaio é a forma da categoria crítica do nosso espírito. Pois quem critica deve também, e necessariamente, conduzir um experimento, deve criar condições sob as quais um objeto se mostra a uma nova luz, deve testar a força ou a fragilidade do objeto - e é por isso que o crítico submete seus objetos a ínfimas variaçóes. (...) em toda boa crítica vige a lei que conserva a variação mínima do objeto - variação que intervém justamente ali onde a grandeza ou a miséria do objeto (...) se tornam plenamente visíveis. O ensaísta trabalha sob a mesma lei, ela define o método de sua experimentação.

Nesse sentido os procedimentos de análise utilizados estarão atrelados aos mesmos exercícios intelectuais que conduzirão a experimentação intelectual que conduzirá toda a atividade: o exercício crítico de debruçarse sobre "uma realidade concreta que se destaca da teoria, a ocorrência concreta de uma ideia, refletida no próprio ensaísta” (Bense, 2014, não paginado).

Escrever ensaísticamente sob força da gravidade de um objeto interdisciplinar que pretenda analisar sob um olhar transdisciplinar não pode escapar às provocações de Bense (2014, não paginado) e resulta numa vinculação direta entre o estilo dessa análise e os resultados que dela derivam:

O escritor se volta para um espaço mais limitado e pacífico que o do poeta, mas nem por isso seu olhar é de comunhão ou meditação, ao contrário: ele é seletivo, imperativo, destrutivo, construtivo, inquieto. Só o escritor movido por uma convicção pode igualmente ser cientista, filósofo, crítico político ou religioso. Talvez seja preciso ter deixado para trás o prazer profundo da criação pura para substituir o canto pela vontade, pela meta ardorosamente perseguida. A mira posta no leitor desvia o 
escritor da criação, assim como a mira na utilidade desvia a ciência da verdade intocável. A paixão sem peias que responde pela criação da obra não se comunica facilmente com a vontade sem peias do espírito que representa uma convicção. A história das ideias nos ensina que o intelectual, o representante de uma convicção, ganha influência e se faz necessário nas épocas difíceis.

Dessa forma, ao privilegiar a forma literária do ensaio como estratégia para a comunicacação dos resultados de uma reflexão, este texto se instala, propositalmente, no território “intermediário entre o estado ético, de um lado, e o estado estético-criativo, de outro”; e, intencionalmente, não se colocando como pertencente a nenhum deles. Ainda, recorrendo ao autor, esta leitura se coloca numa zona intermediária que, de um ponto de vista sociológico, se situaria entre as classes e entre as épocas para encontrar seus confrades e, dali, preparar “as revoluções (explícitas ou silenciosas), as resistências, as subversões”.

\section{Diálogos EPistemológicos diante de uma SituaÇão PANTANosa: PRoblematizando UMA QUESTÃO POR SI SÓ PROBLEMÁTICA}

Se o estudo da relação entre o imaginário e a informação sempre foi um fator crítico para a compreensão da sociedade (ainda que a existência dessa relação raramente seja reconhecida), dado o desafio colocado hoje à sociedade pela condição paradoxal de "transição permanente" (Esprit, 2019) - em que a mudança e a adaptação diante de eventos que se movimentam em alta velocidade se tornaram parte de uma rotina que povoa o quotidiano do fazer e do interagir de indivíduos, grupos e instituições - pode-se observar uma constante busca por refúgio à angústia desencadeada pela perspectiva de mudanças e adaptações constantes.

Essa angústia decorrente do ajuste a frequentes imprevistos aponta para a procura de âncoras seguras na busca e no uso de informações a serem absorvidas nos rituais de respostas ao leque de opçóes que caracteriza a vida social e a ação profissional (Sutherland, 2013). Buscar e trocar informações para reduzir a angústia da incerteza tornou-se uma ação naturalizada e automatizada (Lash, 2002) que ocupa parte significativa do tempo das pessoas e dos grupos.

No entanto, a mesma tecnologia que tornou essa busca acessível e banalizada na interação social por meio de aparatos móveis permitiu o acesso a informações de veracidade questionável de forma igualmente banalizada e acrítica.

Esse problema subjacente de demanda e valorização de informações falsas e da crença nas chamadas verdades alternativas revela uma sensível perda de espaço e da relevância da subjetividade (Hadjadj, 2018) nas equações que dirigem e orientam a ação adaptativa de pessoas e grupos.

Nessas equações, e dentro da já referida cultura da urgência (Aubert, 2003), o suprimento de informação obtido através das fake news é assumido como recurso suficiente para dar conta das demandas de eficácia, entendida como a preservação das propriedades e funções dos eventos diante de imprevistos. Bem antes que a "transição permanente" se tornasse o leitmotiv da sociedade, já se sabia que a eficácia da adaptação não podia ser reduzida apenas a ajustes funcionais, mas dependeria também de que os eventos que pudessem ter sofrido alterações pudessem ser compreendidos. Agregar novas informações, ainda que falsas, para administrar as incertezas e angústias cotidianas repercute diretamente nos sentidos, valores e propriedades dos eventos e, portanto, na sua compreensão. Essa operação mental é feita, inequivocadamente, através do concurso do imaginário. O imaginário, os símbolos, as representações, os valores e as crenças constituem as estruturas subjetivas que mediam as avaliações e, consequentemente, as decisões que norteiam as ações das pessoas e dos grupos em que elas se inserem na sociedade.

Beck e Beck-Gernshein (2002) afirmam que a demanda de rápida adaptação associada à simplificação da compreensão da eficácia, quando limitadas a aspectos funcionais e sob a pressão do tempo, habituaram os indivíduos a priorizarem a funcionalidade de suas respostas. Isso enfraqueceu a atenção que poderia ser dada aos aspectos subjetivos que respondem pelos significados e valores que podem ser alterados por novas informações. Em outras palavras, a aceitação de uma "verdade alternativa" que inspira pouca reflexão tornou- 
se, aparentemente, muito mais interessante do que a consideração a um conteúdo que obrigue ou demande uma reflexão mais aprofundada.

Touraine (2018) nos permite aprofundar o reconhecimento de como o enfraquecimento da subjetivação - que é processo crucial na constituição do sujeito - emergiu como um dos efeitos colaterais da sociedade da informação. Segundo ele, esse enfraquecimento tornou-se cada vez mais reconhecível na vida cotidiana, onde predominam reações imediatas e impensadas que expõem a força mediadora de um imaginário coletivo que naturaliza a apreensão superficial das mensagens e coloca de lado a consideração de possíveis alterações de sentido que elas possam vir a ter.

O movimento essencial para iniciar uma reflexão sobre essa minimização do sentido mais profundo das mensagens poderia ser entabulado a partir da construção de uma epistemologia bio-psico-histórico-social do conhecimento que tome por base o estudo das condições necessárias para o ato de conhecer (e, no caso particular do estudo das fake news: uma epistemologia da informação falsa feita nessas mesmas bases).

Como apontado anteriormente, caso esse estudo se proponha a lançar mão de um campo de ideias que reúna as teorias de Piaget, Gilbert Durand e Carl Gustav Jung como bases para essa nova epistemologia, essa proposta precisaria percorrer um caminho através de conceitos essenciais embora distantes da maioria das reflexões em CI. Um caminho que vá do instinto aos reflexos, dos reflexos aos schèmes, ${ }^{4}$ dos schèmes aos arquétipos, dos arquétipos aos símbolos e dos símbolos ao conhecimento (conforme foi demonstrado em Paula, 2019). Embora, mesmo com o recurso das notas de pé de página, alguns desses termos possam suscitar nos leitores o desconforto esperado diante dos termos inicialmente obscuros, talvez logo o seu papel e a associação entre ele irá se tornar evidente.

Para que essa empreitada seja realizada, será necessário retirar dos instintos o caráter de uma reação automática inferior (inata e não modificável pela experiência) que obrigaria o indivíduo a uma reação estereotipada a um complexo de estímulos (Pieri, 2002) - e elevá-los à dimensão psiquificada que Jung (1991) irá denominar arquétipo. Posteriormente, incorporar de Durand (1997) a vinculação da origem do arquétipo a um conceito anterior, o schème, para, analogamente ao que propôs Piaget, utilizá-lo como o elemento que conectaria os gestos inconscientes da sensório-motricidade, os reflexos dominantes e as representações mentais. Essa complexa proposição inicial será apresentada e irá se tornar mais clara nos parágrafos subsequentes.

A partir do alinhavo entre esses múltiplos domínios teóricos, e numa tentativa de esclarecê-lo, pode-se apontar para o fato de que a "revolução cognitiva" postulada por Harari (2017) como explicação para a ascenção do Homo sapiens foi possibilitada pelo imaginário e alicerçada em símbolos que evocam afetos e cognições. Artefatos cognitivos por excelência, os símbolos (Paula, 2011) seriam elaborações mentais capazes de conectar, através da construção de um terceiro elemento integrativo, dois ou mais elementos diferentes e de difícil compreensão ou elaboração. $\mathrm{O}$ aflorar de um símbolo (ou do próprio símbolo enquanto uma entidade na cognição humana) seria fruto de um processo longo de estruturação da mente a partir da ação no homem em seu ambiente numa relação que só pode ser explicada através de uma leitura ampliada da relação entre conceitos de schème e arquétipos. Para possibilitar essa ampliação, é necessário construir um estudo que possa fundir as noções durandiana e piagetiana de schème tomando-as como parte dos processos lógicos de construção das noções de tempo, espaço e causalidade e considerando-as como essenciais ao processo natural de desenvolvimento da mente como base para a apreensão simbólica / mental do mundo - como queria Fordham (1980).

Nessa perspectiva, todas as construções e elaborações que o homem compõe sobre si e o mundo em que ele habita seriam: a) iniciadas pela conversão, através das estruturas mentais nada programadas específicas para o ato de conhecer (Ramozzi-Chiarottino, 1988), dos reflexos sensório-motores em schèmes (conforme proposto por Durand e Piaget); e b) subsequentemente, produzidas sob a regência dos arquétipos estruturadores decorrentes desses schèmes. Os arquétipos que povoam o imaginário e estruturam a mente iriam se formando e sendo incorporados ao repertório para a organização mental durante o desenvolvimento 
das capacidades cognitivas dos indivíduos e adquirindo uma débil e temporária estabilidade. Estabilidade desafiada e subvertida a cada pequena experiência vivida que produzisse uma desequilibração e que se tornaria ingrediente para uma nova construção transitória ao final de cada processo de reequilibração. Um repertório constantemente bombardeado pelas narrativas, expectativas, visões e percepções dos indivíduos que cercam esse sujeito. O legado de tudo isso seria a capacidade humana para consolidar seus esforços para a organização do mundo ou, em linguagem contemporânea, para a produção, organização e interpretação da informação, a construção de conhecimentos e a atribuição de sentido ao mundo.

Essa atribuição é uma faculdade geradora de conforto por simplificar o universo, proteger os indivíduos do terror produzido pela consciência do fortuito e do acaso, colocá-lo sob uma forma simples e organizada e reduzí-lo com mais facilidade a dimensões cognoscíveis. Dentro dos próprios parâmetros do estudo conduzido até aqui, a tendência humana a abraçar narrativas simplificadoras do mundo é um esforço extremamente bem sucedido da mente, utilizando-se do recurso do imaginário de se apropriar delas (ou de se vincular às "ficções", nas palavras de Harari, 2017) para construir um abrigo seguro contra a angústia de confrontar a incerteza do universo circundante (e a percepção do fim da nossa experiência individual, como poderia sugerir Durand, 1997).

Dentro desse contexto, pode-se sugerir que para tornar possível a investigação do contexto atual das ficções que povoam os fenômenos infocomunicacionais contemporâneos - como aquele suscitado, por exemplo, pelas "pós-verdades" e fake news - de maneira objetiva e imparcial é preciso levar as pesquisas sobre a informação a transporem "uma categoria de estudos baseados em conceitos como "livro", "documento" e "escrita", ou ainda, "esquema" (Saldanha, 2018, p. 12)" (entendendo esquema como schéma, um tipo de representação figurativa de uma ideia, um desenho ou diagrama), para outra categoria fundamentada na compreensão dos schème como instrumentos mentais de generalização que permitam destacar os elementos comuns a condutas análogas sucessivas. Em outras palavras, promover um processo de schèmetization que abarcasse todo o campo informacional ou, no mínimo, estabelecer essa schèmetization como sua disciplina central no plano epistemológico.

\section{Apontando CAMinhos E aCENANDO COM PROPOSTAS}

Cogitar o desenvolvimento de bases bio-psico-histórico-sociais para uma schémetization do campo informacional com vistas ao combate da desinformação a partir da compreensão da ecologia mental que a sustenta envolveria trilhar uma serie de percursos complementares:

\subsection{Construir uma ponte conceitual entre às noções de schème em Piaget e Durand que permita avaliar a adequação de sua integração a uma epistemologia crítica do campo e, consequentemente, à criação de uma abordagem integradora para as teorias que se dedicam ao entendimento do conceito de informação}

O conceito de schème foi apresentado por Piaget em sua obra Biologie et connaissance (Piaget, 1967). Trata-se de um conceito que aglutina a complexidade e operacionalidade do sujeito nas situaçóes que fundam não somente a construção do conhecimento como também a construção da noção do real.

A identificação dos schèmes de ação como os elementos que, em uma ação, podem ser transportados, generalizados ou diferenciados de uma situação para a seguinte, parece conversar de maneira muito próxima com o conceito de schéme utilizado por Durand.

Em ambas as utilizações, o elemento central são as capacidades para a construção do conhecimento e para a significação do mundo. Visualiza-se aqui um conceito de potencial utilidade para as teorias que tem a informação como objeto de estudo. 


\subsection{Caracterizar a ecologia mental da desinformação como sustentação da disseminação e crença em informações falsas}

Baseando-se no conceito de ecologia (tomada como a ciência de compreender as relações entre os seres vivos e o seu meio ambiente), Thomas Davenport (1998) criou o termo Ecologia da Informação para explicitar o fato que somente o domínio da tecnologia não bastava para a sobrevivência na sociedade da informação. Preocupado com questões como inteligência artificial (IA), big data e transformação digital, o autor preocupava-se em integrar três ambientes: o ambiente externo à organização (composto por negócios, informação e tecnologia); o ambiente organizacional (composto por negócios, espaço físico e tecnologia); e o ambiente informacional.

A ideia do autor era que a utilização da expressão ecologia como metáfora pudesse descrever o relacionamento íntimo entre os diversos tipos de informação (não estruturada, estruturada em papel e estruturada numa base informatizada).

Propõe-se, aqui, a transposição dessa metáfora para a descrição e a compreensão das bases psicológicas segundo as quais a crença nas informações falsas se sustenta e é disseminada.

\subsection{Realizar a transposição da abordagem para modelos evolutivos de transferência de informações culturais proposta pela memética para o campo informacional}

A memética foi proposta como o estudo da informação e da cultura a partir de uma analogia com os princípios da evolução darwiniana. Descrita como uma abordagem para modelos evolutivos de transferência de informações culturais, a memética busca explicações sobre como certas ideias possam se propagar com sucesso, mesmo a despeito de não serem verdades factuais. O termo meme foi cunhado por Dawkins (2007) como um análogo mental a um gene - uma "unidade de cultura" (base de ideias, crenças, e padrões de comportamento) que seria "hospedada" nas mentes de um ou mais indivíduos e que, assim, poderia "se reproduzir" a partir da comunicação entre as pessoas. Dessa forma, um proselitista e os meios segundo os quais ele dissemina as suas ideais seriam vistos como um mecanismo replicador de ideias que se reproduzem em novos hospedeiros.

É na proposta de Dawkins (2007), segundo a qual o sucesso de um meme específico se deveria à sua contribuição para a eficácia da ação de seu hospedeiro no mundo, e na sua definição de meme como "uma unidade de informação", que se configura a possibilidade de construir um modelo para a compreensão da propagação das ideias falsas e, consequentemente, para um aprofundamento das reflexões sobre o próprio conceito de informação no campo dos estudos informacionais. Um bom (ou uma conjunto de bons/boas) meme, ou uma boa unidade mínima de informação, não é bom porque é faticamente correto, é bom porque resolve o problema de complexidade do mundo e "acalma" seu "hospedeiro" diante da angústia que essa complexidade provoca.

\subsection{Traçar um paralelo entre a utilização do termo schèma e da teoria da schematization pela Escola Esquematista da Ciência da Informação e a possível utilização do conceito schéme e uma teoria da schemetization como base para a redefinição do campo informacional suscitada pelos problemas da condição hipermoderna}

A Escola Esquematista da Ciência da Informação, criada por Robert Estivals, em diálogo com seus antecessores epistemólogos, Paul Otlet, Nicolas Roubakine e Gabriel Peignot em oposição às suas congêneres library science, library and information science e information science, oriundas das universidades norte- 
americanas, constitui-se como uma teoria do conhecimento para o campo informacional. Sustentada pelos estudos de Nicolas Roubakine e sua bibliopsicologia ela constrói sua base epistemológica a partir do conceito de "esquema" (schèma) e na teoria da "esquematização" (schèmatization). A relevância atribuída ao conceito de schèma - que, nos dizeres de Saldanha (2018), integra as perspectivas teóricas e metodológicas do devir do campo infocomunicacional - foi responsável por demarcar uma "abertura disciplinar e dos diálogos teóricos com correntes artísticas, cognitivas, tecnológicas, políticas e econômicas, atravessando os diferentes territórios teóricos do campo" sem precedentes. A proposta desse caminho é, a partir da introdução do conceito schéme (tratada no caminho 4.2) e de uma teoria da schemetization - ampliar a proposta de reconstrução do mundo simbólico a partir das ferramentas críticas desenvolvida pela escola esquematista e, quem sabe, até mesmo apontar parâmetros para uma redefinição do campo informacional em função dos dilemas da hipermodernidade.

\subsection{Demarcar, a partir da abertura disciplinar que uma teoria da schemetization proporciona para diálogos teóricos entre correntes sociais, cognitivas, tecnológicas, políticas e econômicas envolvidas na discussão de problemas infocomunicacionais, a definição de um território informacional propositivo e voltado para a solução de questões prementes como a urgência da alfabetização midiática e de conscientização para a importância da comunicação online numa perspectiva crítica}

A proposta aqui seria de retomada da história "que vai da "ciência do livro" (Peignot, 1802), à "ciência do livro e do documento" (Otlet, 1934) ${ }^{6}$ e à "ciência da escrita" (na mais plural acepção e no mais crítico uso da noção de escrita passível de serem desenvolvidos)" (Saldanha, 2018, p. 205), passando da noção de "bibliologia" como uma ampla denominação que viria abarcar todo o campo informacional (que vai além de conceitos como "livro", "documento" e "escrita", ou ainda, "esquema") para, a partir da introdução do conceito de schème, estender as preocupações do campo informacional do estudo da informação representada para a investigação das condiçes que possibilitam a sua representação. Finalmente, a partir desse movimento, seria possível definir um território informacional propositivo e voltado para a solução das questões suscitadas pela hipermodernidade.

6. O PROJETO DE UM SONHO INDISCIPLINADO, OU, SOBRE O QUE É POSSÍVEL DE SER CONCLUÍDO

Por se tratar de um projeto especulativo sobre possibilidades, o presente ensaio propõe para aquelas pessoas que se dispuserem a abraçá-lo, o mergulho, nos dizeres de Riberio (2019), em um oráculo probabilístico. Um exercício semelhante ao sonho, que envolverá simular cenários prováveis para área e para o futuro das situações aos quais ela se dedica tomando como base o passado, recente ou não, não somente da área da Ciência da Informação, mas de todas as outras disciplinas que constituem o que aqui se denominou campo informacional, e especular (no sentido filosófico) a partir de suas teorias e concepções muitas vezes concorrentes. Buscar, ainda evocando Ribeiro (2019), imaginar o amanhã, a partir de probabilidades estabelecidas a partir de informações e conhecimentos recuperados do ontem.

Um projeto que, ao longo e ao final de seu desenvolvimento, necessitará evocar a essência da Escola Esquematista da Ciência da Informação (Saldanha, 2018), estabelecendo ações práticas como decorrência natural de suas reflexões sempre marcadas por interrelações e sobreposições com uma versão específica de teoria do conhecimento para o campo informacional, bem como com a sua historicidade e uma firme 
convicção quanto à relação, no plano político, entre comunicação e informação e um firme posicionamento e ação política quanto a isso.

Nesse sentido, será preciso buscar ações efetivas para a divulgação dos resultados conceituais alcançados e a busca por aplicá-las em ações práticas. No plano intelectual, uma forma de oferecer contribuições não apenas para o desenvolvimento da Ciência da Informação, mas também das várias áreas envolvidas na pesquisa. Não apenas propor classes para ensinar sobre como conduzir estudos transdisciplinares, mas embasar pragmática e politicamente (no melhor estilo freiriano, Freire, 1992) a atuação transdisciplinar em ensino, pesquisa e extensão. A ideia seria aproveitar esse espaço para criar um território de interações onde a expertise dos interagentes envolvidos (pesquisadores ou não) possa ser aproveitada para enriquecer o debate proposto por esse projeto sobre o tema da desinformação e possíveis estratégias para combatê-los, mas, simultaneamente, explorar essas interações até os limites de onde as eventuais reflexões e produtos desse esforço possam ser aproveitados, como uma forma de retribuição, por todas as áreas individuais que se envolverem nele.

Além de possíveis contribuições para as subáreas dos Estudos Históricos e Epistemológicos da Ciência da Informação e de Mediação, Circulação e Apropriação da Informação, o sucesso de uma empreitada nessa direção poderia contribuir para a formação de multiplicadores aptos a desenvolver ações no campo da alfabetização midiática e da conscientização quanto à importância da comunicação online.

Nesses termos, se inscreve aqui o sonho/projeto da operacionalização de uma maior relação entre teoria e prática voltada para a democratização do conhecimento produzido no exercício das investigaçóes no campo e o posterior retorno desse saber a ele após ter sido testado e reelaborado. Esse exercício de diálogo entre os pesquisadores de vários níveis envolvidos no projeto, a comunidade acadêmica e a sociedade pode ser dar a partir do eixo ensino / extensão propondo ações de formação contextualizadas a questóes prementes sociedade contemporânea (como, por exemplo, os já citados ecossistemas de desinformação, o controle dos algoritmos sobre as redes sociais, o capitalismo de vigilância e as consequências da ação indiscriminada e não regulada dos bots de internet) e; a partir do eixo ensino / pesquisa, buscando a capacitação de jovens pesquisadores no uso de instrumentos que os habilitem à dar continuidade ao seu interesse de compreensão do mundo que os circunda e à sua formação como pesquisadores criativos e inovadores.

\section{REFERÊNCIAS}

Antunes, M. L. A. (2015). Comportamento informacional em tempos de Google. [Dissertação de Mestrado (Ciência da Informação), Universidade Federal de Minas Gerais, Belo Horizonte].

Araújo, E. P. de O. (2013). Tomada de decisão organizacional e subjetividade: análise das dimensóes simbólico-afetivas no uso da informação em processos decisórios. [Dissertação de Mestrado (Ciência da Informação), Universidade Federal de Minas Gerais, Belo Horizonte].

Araújo, E. P. de O. (2017). Comportamento informacional em processos decisórios estratégicos: dimensão simbólica do uso da informação por gestores. [Tese de Doutorado (Ciência da Informação), Universidade Federal de Minas Gerais, Belo Horizonte].

Aubert, N. (2003) Le culte de L'urgence: la société malade du temps. Paris: Flammarion.

Beck, U. \& Beck-Gernshein, E. (2002). Individualization. London: Sage.

Bense, M. (2014). O ensaio e sua prosa. Revista Serrote, 35-36. Recuperado de https://www.revistaserrote.com.br/2 014/04/o-ensaio-e-sua-prosa/

Biblioteca Dante Moreira Leite - Instituto de Psicologia - IP/USP (s.d). O que é revisão de literatura? São Paulo: Universidade de São Paulo.

Boechat, W. (2018). Complexo cultural e brasilidade. In Desvelando a alma brasileira (pp. 68-87). Petrópolis: Vozes.

Bueno, E. (1999). Capitães do Brasil: a saga dos primeiros colonizadores. Rio de Janeiro: Objetiva.

Cavalcante, C. A. e Cavalcanti, A. P. (2015) O que é o imaginário? Olhar biopsicossocial da obra transdisciplinar de Gilbert Durand. João Pessoa: Editora UFPB. 
Davenport, T. (1998). Ecologia da informação. São Paulo: Futura.

Dawkins, R. (2007). O gene egoísta. São Paulo: Companhia das Letras.

Durand, G. (1997). As estruturas antropológicas do imaginário. São Paulo: Martins Fontes.

Eco, U. (2017). Pape Satàn Aleppe: crônicas de uma sociedade líquida. Rio de Janeiro: Record.

Esprit. (2019). Éditorial. La transition permanente. Esprit: Le sens de l'école (dossier), septembre.

Figueiredo, L. C. M. (1992). A invenção do psicológico: quatro séculos de subjetivação. S. Paulo: Escuta/Educ.

Fordham, M. (1980). The emergence of child analysis. Journal of analytical psychology, 25(4), 311-324.

Freire, P. (1992). Extensão ou comunicação? Rio de Janeiro: Paz e Terra.

Hadjadj, F. (2018). Et le Verbe s'est fait charpentier - ou la Bonne Nouvelle de nos mains, Conference de Carême, Notre Dame de Paris, dimanche 4 de mars.

Harari, Y. N. (2017). Sapiens: uma breve história da humanidade. Porto Alegre, RS: L\&PM.

Jung, C. G. (1991). Considerações teóricas sobre a natureza do psíquico. In C. G. Jung, A dinâmica do inconsciente (volume VIII das obras coligidas). Petrópolis: Vozes.

Keen, A. (2008). O culto do amador: como blogs, Myspace, Youtube e a pirataria digital estão destruindo nossa economia, cultura e valores. São Paulo: Zahar.

Lash, S. (2002). Critique of information. London: Sage.

Maffesoli, M. (2007). O ritmo da vida: variações sobre o imaginário pós-moderno. Rio de Janeiro: Record.

McLuhan, H. (1994). Understanding media. London: Routledge.

Obana, J. E. G. (2015). A epistemologia e a psicologia genética de Jean Piaget e as neurociências: uma revisão sistemática [Dissertação de Mestrado. Faculdade de Filosofia e Ciências. Marília (SP): Universidade Estadual Paulista Julio de Mesquita Filho (UNESP), Marilia]. Recuperado de https://repositorio.unesp.br/bitstream/handle/11449/ 123932/000832880.pdf?sequence $=1$ \&isAllowed $=y$

Paula, C. P. A. de (1999). Informação e Psicodinâmica organizacional: um estudo teórico. 206 f. [Dissertação de Mestrado (Ciência da Informação), Universidade Federal de Minas Gerais, Belo Horizonte, Minas Gerais, Brasil].

Paula, C. P. A. de (2005). O simbolo como mediador da comunicação nas organizações: uma abordagem junguiana das relaçôes entre a dimensão afetiva e a produção de sentido nas comunicaçôes entre professores do departamento de Psicologia de uma instituição de ensino superior brasileira. $367 \mathrm{f}$. Tese [Tese de Doutorado (Psicologia Social e do Trabalho), Universidade de São Paulo, São Paulo, Brasil].

Paula, C. P. A. de (2011). Dimensões simbólicas e afetivas do uso da informação: uma análise das comunicações entre professores do departamento de psicologia de uma instituição de ensino superior pública brasileira. In XII ENANCIB, 2011. Anais do XII ENANCIB (pp. 1-20). Brasilia: UNB Brasilia.

Paula, C. P. A. de (2012a). Dimensões simbólicas e afetivas do uso da informação: uma análise das comunicações entre professores do departamento de psicologia de uma instituição de ensino superior pública brasileira. Perspectivas em gestão \& conhecimento, 2, 118-132.

Paula, C. P. A. de (2012b). Proposta de metodologia para a investigação do comportamento de busca informacional e do processo de tomada de decisão dos líderes nas organizações: introduzindo uma abordagem clínica na informação. In XIII ENANCIB. Anais do XIII ENANCIB. Rio de Janeiro.

Paula, C. P. A. de (2013). A investigação do comportamento de busca informacional e do processo de tomada de decisão dos líderes nas organizações: introduzindo a abordagem clínica da informação como proposta metodológica. Perspectivas em gestão \& conhecimento, 3, 30-44.

Paula, C. P. A. de (2019). Reflexões sobre o conceito de arquétipo numa perspectiva não metafísica: um diálogo sobre sua origem no mudo físico e os eu papel na organização do mundo através da mente. In E. S. Lind, H. J. P. Moraes, Mídia cotidiano e imaginário. João Pessoa: Editora UFPB.

Pedrosa, C. G. (2017). A dimensão subjetiva da gestão de bibliotecas universitárias. [Dissertação de Mestrado (Ciência da Informação), Universidade Federal de Minas Gerais, Escola de Ciência da Informação. Belo Horizonte]. 
Piaget, J. (1967). Biologie et connaissance: essai sur les relations entre les régulations organiques et les processus cognitifs. Paris: Gallimard.

Pieri, P. F. (2002). Dicionário Junguiano. São Paulo: Paulus.

Queiroz, T. P. (2014). O bom filho a casa sempre torna: análise do relacionamento entre a Universidade Federal de Minas Gerais e seus egressos por meio da informação. 202f. [Dissertação de Mestrado (Ciência da Informação), Universidade Federal de Minas Gerais, Belo Horizonte].

Queiroz, T. P. (2019). Conhece-te a ti mesmo: a percepção dos egressos sobre a imagem de um curso de graduação em Biblioteconomia. [Tese de Doutorado (Ciência da Informação), Universidade Federal de Minas Gerais, Belo Horizonte].

Ramozzi-Chiarottino, Z. (1988). Psicologia e epistemologia genética de Jean Piaget. São Paulo: EPU.

Ribeiro, S. (2019). O oráculo da noite: a história e a ciência do sonho. São Paulo: Companhia das Letras.

Rocha, J. A. P. (2018) A produção do conhecimento como cognição distribuida: práticas informacionais no fazer científico. [Tese de Doutorado (Ciência da Informação), Universidade Federal de Minas Gerais, Escola de Ciência da Informação. Belo Horizonte, Minas Gerais].

Sá, R. M. C. de. (2015) Compartilhamento do conhecimento e o processo de orientação de discentes de pós-graduação stricto sensu. [Dissertação de Mestrado (Ciência da Informação), Universidade Federal de Minas Gerais, Escola de Ciência da Informação. Belo Horizonte].

Saldanha, G. S. (2018). Epistemologia crítica e social da ciência da informação: 50 anos de uma escola dialética. In: XIX ENANCIB. Anais do XIX ENANCIB (pp. 1-20). Londrina: Universidade Estadual de Londrina.

Spotts, F. (2003). Hitler and the Power of Aesthetics. Woodstock, New York: Overlook Press.

Sutherland, T. (2013). Liquid networks and the metaphysics of flux: ontologies of flow in an age of speed and mobility. Theory culture \& society, 30(5), 3-23. Recuperado de https://journals.sagepub.com/doi/10.1177/0263276412 469670

Touraine, A. (2018). Nous sujets humaines. Paris: Seuil.

Xavier, R. C. M., \& Costa, R. O. da. (2010). Relações mútuas entre informação e conhecimento: o mesmo conceito?. Ciência da informação, 39(2), 75-83. Recuperado de https://dx.doi.org/10.1590/S0100-19652010000200006

\section{Notas}

1 Concorda-se aqui com Figueiredo (1992) quando este afirma que a chamada condição pós-moderna apenas expressa uma situação de exacerbação dos movimentos iniciados no período das grandes navegações e que deu início à idade moderna (entre eles a multiplicação das vozes, da velocidade das transformações e um aumento gigantesco do volume de informações circulando). Hipermodernidade será, portanto, o termo adotado aqui para caracterizar o momento histórico em que este estudo é proposto.

2 Versão contemporânea do Bolchevismo Cultural (Kulturbolschewismus, em alemão), termo utilizado na Alemanha Nazista para "denunciar" os movimentos modernistas nas artes e, depois, estendido para criticar, todos os argumentos que buscavam desacreditar os argumentos e raciocínios niilistas que sustentavam o discurso do regime Spotts (2003).

3 Ver observação sobre a Abordagem Clínica da Informação - ou, ACI - e a sua relação com o método clínico em Paula (2011, 2012b).

4 Os schème, segundo Cavalcanti e Cavalcanti (2015) seriam, simplificadamente, uma impressão duradoura deixada na mente por um estímulo ambiental. Essas impressões duradouras estariam assentadas em três grupos básicos de reflexos verificados em bebês neonatos e que estariam na base do despertar sensório-motor de cada indivíduo.

5 O autor se refere a Peignot, G. (1802). Dictionnaire raisonné de bibliologie, tomo I. Paris: Chez Villier.

6 O autor se refere a Otlet, P. (1934). Traité de documentation: le livre sur le livre: théorie et pratique. Bruxelas: Editiones Mundaneum. 